\title{
Isolated Medial Subtalar J oint Dislocation during Soccer (Football) Game: A Case Report and Review of the Literature
}

\begin{abstract}
Fekhaoui MR ${ }^{1 *}$, Bassir R-A ${ }^{2}$, Mekkaoui J ${ }^{1}$, Boufettal $M^{2}$, Kharmaz $\mathbf{M}^{1}$, Lamrani $\mathbf{M O}^{1}$ and Berrada MS ${ }^{1}$

'Department of Trauma and Orthopedic Surgery, Ibn Sina University Hospital, Faculty of Medicine, Mohammed V University of Rabat, Rabat, Morocco

${ }^{2}$ Department of Anatomy, Faculty of Medicine, Mohammed V University of Rabat, Rabat, Morocco

*Corresponding author: Mohammed Reda Fekhaoui, Department of Trauma and Orthopedic Surgery, Ibn Sina University Hospital, Faculty of Medicine, Mohammed V University of Rabat, Rabat, Morocco
\end{abstract}

Received: August 10, 2021; Accepted: August 30, 2021; Published: September 06, 2021

\begin{abstract}
Ankles injuries are common in sports such as football and soccer and one of the most serious and most rare is the subtalar dislocation. This injury is rare, touches young male patients and usually associated to fractures of the talus, the malleoli or the fifth metatarsal. Usually, this injury occurs in high-energy trauma, but it is very rare in sports injuries. Here we present the case of a 36-year-old male with an isolated Medial Subtalar Joint Dislocation after a severe tackle in a football (soccer) game. We performed a closed reduction under general anesthesia, and then a short-leg cast was applied for 4 weeks, followed by active and passive range of motion. At one-year follow up from trauma, the patient had a pain-free ankle with active full range of motion. For isolated medial subtalar dislocation occurring during sports activities, the first choice is the conservative treatment: Immediate closed reduction needs to be achieved followed by a short immobilization. Active/passive range of motion need to be started early to avoid joint stiffness.
\end{abstract}

Keywords: Subtalar; Dislocation; Soccer; Joint; Isolated; Medial

\section{Introduction}

Ankles injuries are common in sports such as football and soccer [1] and one of the most serious and most rare is the subtalar dislocation. It is the dislocation of two joints: the talocalcaneal and the talonavicular joints [2]. This injury is rare, touches young male patients [1] and usually associated to fractures of the talus, the malleoli or the fifth metatarsal [3]. In English literature, there are a few cases of isolated dislocation of the subtalar joint [4] and the medial form represent $80 \%$ [2]: the calcaneus and the rest of the foot dislocate laterally in relation to the talus [4]. Usually, this injury occurs in highenergy trauma, such motor or vehicle accidents [5] but it is very rare in sports injuries [6]. Here, we present the case of a 36-year-old male with an isolated Medial Subtalar Joint Dislocation after a severe tackle in a football (soccer) game.

\section{Case Presentation}

A 36-year-old male patient was addressed to our department for an ankle trauma after a sport injury (severe tackle during a football soccer game). He presented with a grossly deformed right ankle in medial plantar flexion (Figure 1). Radiographs (AP and lateral view of the right ankle) confirmed the diagnosis of an isolated medial subtalar joint dislocation: the calcaneus and the rest foot were dislocated medially in relation to the talus (Figure 2). In the operating room, we performed a closed reduction under general anesthesia. The ankle was stable and the reduction was confirmed fluoroscopically. A short-leg cast was applied for 4 weeks with no weight bearing. On the post-reduction radiographs, the dislocation was reduced (Figure 3). At 4 weeks follow up, the cast was removed then passive and active range of motion exercises was started with partial weight bearing. Full weight bearing was allowed after 12 weeks. At one-year follow up

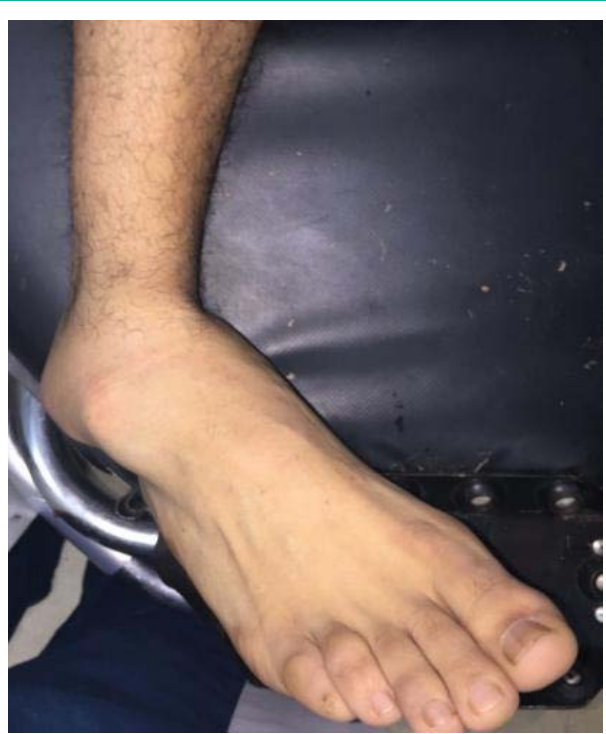

Figure 1: Clinical image showing a deformed right ankle in medial plantar flexion.

from trauma, the patient had a pain-free ankle with active full range of motion.

\section{Discussion}

The medial subtalar joint dislocation is a rare injury, which accounts $<1 \%-2 \%$ of all foot dislocations $[7,8]$. The most common cause is a fall from height [9]. In this injury, the both navicular and calcaneus dislocate in relation to the talus [3]. There are 3 types of subtalar dislocation, based on the direction of the rest foot and
Austin J Orthopade \& Rheumatol - Volume 8 Issue 2 - 2021 ISSN: 2472-369X | www.austinpublishing group.com

Fekhaoui et al. (C) All rights are reserved
Citation: Fekhaoui MR, Bassir R-A, Mekkaoui J, Boufettal M, Kharmaz M, Lamrani MO, et al. Isolated Medial Subtalar Joint Dislocation during Soccer (Football) Game: A Case Report and Review of the Literature. Austin J Orthopade \& Rheumatol. 2021; 8(2): 1102. 


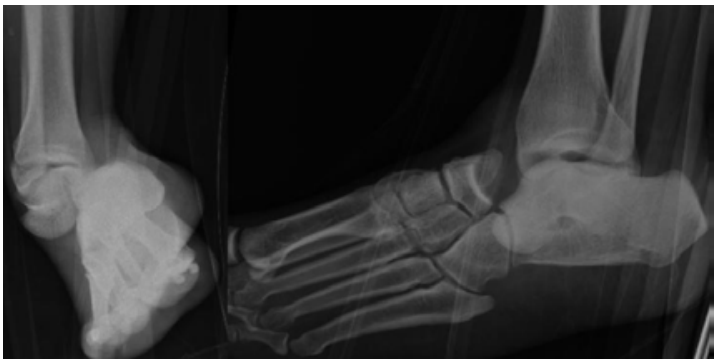

Figure 2: Antero-posterior and lateral radiographs of the right ankle showing an isolated medial subtalar joint dislocation with the calcaneus and the rest foot dislocated medially in relation to the talus.

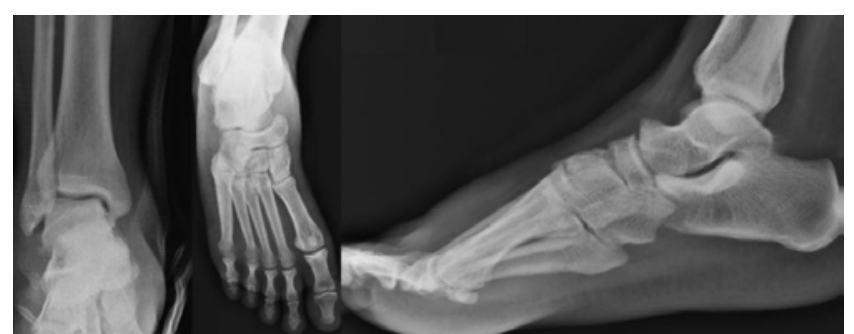

Figure 3: Post-reduction radiographs of the right ankle showing the reduction of the medial subtalar dislocation.

calcaneum in relation to the talus: medial, lateral and posterior subtalar joint dislocation [7]. Later, an anterior form was added by Malaigne and Burger [10]. Medial dislocation is caused by a forced inversion of the forefoot, the talocalcaneal and talonavicular ligaments break, the talus remains in his normal position at and subtalar joint dislocation occurs [4]. For isolated medial subtalar dislocation occurring during sports activities, the first choice is the conservative treatment [2]. In 33 studies about 439 patients with isolated subtalar dislocation, $85 \%$ were treated with closed reduction followed by immobilization for 3 to 6 weeks and good to excellent results were obtained [11-16]. The period of immobilization remains controversial [3]. Some authors [17] reported that reducing the period of immobilization could decrease the rate of joint stiffness. Others judged that 4 weeks period remains insufficient time for healing $[10,18,19]$. In our case, after a closed reduction, a short-leg cast was applied for 4 weeks followed by active and passive range of motion to avoid joint stiffness, as recommended by most authors [4]. Posttraumatic arthritis, osteonecrosis of the talus and subtalar joint stiffness are the most severe long-term complications [20], and we do not report any of these complications in our patient. At one-year follow up from trauma, our patient had a pain-free ankle with active full range of motion, even if $80 \%$ of subtalar dislocations demonstrate a small decrease of the subtalar and/or ankle range of motion [21].

\section{Conclusion}

Isolated medial subtalar dislocations usually occur in highenergy trauma, but it is very rare in sports injuries. The first choice is the conservative treatment. Immediate closed reduction needs to be achieved followed by a short immobilization then active/passive range of motion to avoid joint stiffness, as recommended by most authors.

\section{References}

1. Smith $\mathrm{T}$, Ballard $\mathrm{T}$, Ramanlal $\mathrm{R}$, et al. Foot Dislocation. In: StatPearls Publishing: Treasure Island, FL, USA. 2020.

2. Biz C, Baldin G, Cappelletto C, et al. Isolated Medial Subtalar Joint Dislocation during Sports Activities: A Systematic Review of the Literature with Individual Participant Data Analysis. Osteology. 2021; 1: 48-61.

3. Perugia D, Basile A, Massoni C, et al. Conservative treatment of subtalar dislocations. Int Orthop. 2002; 26: 56-60.

4. Giannoulis D, Papadopoulos DV, Lykissas MG, Koulouvaris P, Gkiatas I, Mavrodontidis A. Subtalar dislocation without associated fractures: Case report and review of literature. World J Orthop. 2015; 6: 374-379.

5. Biz C, Ruaro A, Giai Via A, Torrent J, Papa G, Ruggieri P. Conservative management of isolated medial subtalar joint dislocations in volleyball players: a report of three cases and literature review. J Sports Med Phys Fitness. 2019; 59: 1739-1746.

6. Camarda L, Abruzzese A, La Gattuta A, Lentini R, D'Arienzo M. Results of closed subtalar dislocations. Musculoskelet Surg. 2016; 100: 63-69.

7. Rammelt S, Goronzy J. Subtalar dislocations. Foot Ankle Clin. 2015; 20: 253264.

8. Bryson D, Khan Z, Aujla R, Bromage JD. A near miss: an uncommon injury following a common mechanism. BMJ Case Rep. 2011; 2011: bcr0420114086.

9. Ruhlmann F, Poujardieu C, Vernois J, Gayet LE. Isolated Acute Traumatic Subtalar Dislocations: Review of 13 Cases at a Mean Follow-Up of 6 Years and Literature Review. J Foot Ankle Surg. 2017; 56: 201-207.

10. Zimmer TJ, Johnson KA. Subtalar dislocations. Clin Orthop Relat Res. 1989: 190-194.

11. Jungbluth P, Wild M, Hakimi M, Gehrmann S, Djurisic M, Windolf J, et al Isolated subtalar dislocation. J Bone Joint Surg Am. 2010; 92: 890-894.

12. Bak K, Koch JS. Subtalar dislocation in a handball player. Br J Sports. 1991; 25: 24-25.

13. Kinik H, Oktay O, Arikan M, Mergen E. Medial subtalar dislocation. Int Orthop. 1999; 23: 366-367.

14. Tabib W, Lemonne F, Aboufarah F, Nguyen Duy T, Asselineau A, Bombart $M$. Anterior subtalar dislocation associated with a fracture of the calcaneus: a case report and review of the literature. Rev Chir Orthop Reparatrice Appar Mot. 2000; 86: 197-203.

15. Hadji M, Golli M, Moalla R, Kmantar L, Hamdi A. Conservative treatment of talar dislocation: a case report. Rev Chir Orthop Reparatrice Appar Mot. 2004; 90: 285-288.

16. Cilli F. Limitation in subtalar motion in a patient nine years after treatment for medial subtalar dislocation. Acta Orthop Traumatol Turc 2006; 40: 173-175.

17. Byrd ZO, Ebraheim M, Weston JT, Liu J, Ebraheim NA. Isolated subtalar dislocation. Orthopedics. 2013; 36: 714-720.

18. DeLee JC, Curtis R. Subtalar dislocation of the foot. J Bone Joint Surg Am. 1982; 64: 433-437.

19. Buckingham WW, LeFlore I. Subtalar dislocation of the foot. J Trauma. 1973; 13: 753-765.

20. Freund KG. Subtalar dislocations: a review of the literature. J Foot Surg. 1989; 28: 429-432.

21. Heppenstall RB, Farahvar H, Balderston R, Lotke P. Evaluation and management of subtalar dislocations. J Trauma. 1980; 20: 494-497. 